\title{
PERANAN PEMBIMBING AGAMA ISLAM DALAM MEMBERIKAN MOTIVASI PENTINGNYA BELAJAR AL-QUR'AN DI MAJELIS TAKLIM BANDUNGAN KAMPUNG SAWAH LEGA KECAMATAN PASIRWANGI KABUPATEN GARUT
}

\author{
Muhammad Saepul Ulum \\ STAI YAPATA AL JAWAMI Bandung \\ $\underline{\text { m.saepululum24@gmail.com }}$
}

\begin{abstract}
The focus of this research is the members of the Bandungan Taklim Assembly of Kampung Sawah Lega, Pasirwangi Subdistrict, Garut Regency, which notes the background of the farmers who have concerns about the importance of learning the Qur'an, which in their daily life every morning until evening takes care of their agricultural land in the mountains and rice fields. and in the evening gather with family members so that at an advanced age they want to try to get closer to the almighty Allah Almighty by studying reading the Qur'an in the Taklim Bandungan Assembly. This research was conducted at the Taklim Bandungan Assembly. The formulation of the problem in this study is how the Motivation of Learning Qur'an at the Taklim Bandungan assembly and how the Role of Islam in Increasing the motivation of importance of Learning the Qur'an at the Taklim Bandungan Assembly. The research method used in this study is a qualitative research with descriptive design, a case study method with a phenomenological approach, the informants in this study consisted of 1 Islamic religious counselor and 4 members of the Bandungan Taklim Assembly Jama'ah who routinely attend recitals every week. The data collection techniques using in this research are observation, in-depth interviews and documentation. The results achieved from this study indicate that the role of Islamic religious supervisors is very important in increasing the motivation of the importance of learning the Koran for the Jama'ah Taklim Bandungan Assembly, in the process of Islamic religious guidance beginning with the recitation of the Qur'an simultaneously which then proceed with the Koran independently by listening and observing the supervisors and other worshippers continued tausiyah and Question and Answer. The method of giving motivation is used by religious counselors, namely the one-way lecture method and the question and answer process.
\end{abstract}

Keywords: Islamic Religion Supervisor, Motivation, Al-Qur'an Learning 


\section{A. Pendahuluan}

Pada dasarnya, bimbingan agama merupakan suatu proses pengajaran kepada orang lain dalam situasi dan kondisi tertentu, pada semua kelompok usia, serta dilakukan secara berkesinambungan (contineu). Hal ini juga berlaku pada orang yang mengalami hambatan atau kesulitan dalam hidupnya; sehingga bantuan atau pertolongan yang diberikan dapat menuntunnya kearah yang lebih baik. Selain itu juga, bimbingan agama dapat meningkatkan potensi seseorang untuk mencapai kebahagiaan dunia dan akhirat, baik bagi dirinya sendiri maupun masyarakat sekitarnya.

Bimbingan merupakan suatu proses melayani umat demi mencapai pengetahuan serta kereativitas. Ini dilakukan untuk penyesuaian diri dan membantu individu atau kelompok dalam mengenal berbagai informasi mengenai diri mereka masingmasing.

Dalam bukunya Walgito menyatakan bahwa: "Pembimbing agama ialah salah satu usaha untuk memberikan jalan kepada umat atau jemaahnya yang mengalami kesusahan baik secara lahir maupun batin yang berkaitan dengan kehidupan mereka dimasa sekarang dan kehidupan yang akan datang. Bimbingan tersebut berupa bimbingan mental maupun spiritual, dengan maksud dan tujuan agar senantiasa jamaah tersebut mampu mengatasi kesusahan dengan pemahamannya sendiri, melalui dorongan dan kekuatan keimanan, ketakwaan kepada Allah SWT, oleh sebab itu sasaran Bimbingan Agama ini suatu proses untuk membangkitkan batin ruhaniyah manusia melalui keimanan kepada Allah Ta'ala. ${ }^{1}$

Tujuan Utama dari bimbingan agama adalah memberikan pemahaman kepada seseorang maupun jamaah yang sedang mengalami kerisauan secara ruhaniyah ${ }^{2}$. Hal ini pula terjadi pada jamaah Majelis Taklim Bandungan. Tujuan pembimbing agama pada mereka adalah meningkatkan kualitas keimanan kepada

\section{0), h.4}

${ }^{1}$ Walgito, Bimbingan Penyuluh di Sekolah, (Yogyakarta: Andi Offset,

${ }^{2}$ Hamdi Abdul Karim, Peran Manajemen Dalam Bimbingan Penyuluhan Islam, Jurnal Bimbingan Penyuluhan Islam, Vol.1 No 1 Januari-Juni 2019 hal 121-122 
Allah SWT melalui pembelajaran membaca serta mengamalkan isi Kandungan Al-Qur'an.

Sebagai kitab suci ummat Islam, Al-Qur'an yang secara harfiahnya berarti suatu bacaan sempurna, merupakan suatu nama pilihan Allah Swt yang sungguh amat tepat dan sempurna, karena tiada suatu bacaan pun sejak manusia mengenal budaya baca tulis lima ribu tahun yang lalu, yang dapat menandingi kehebatan Al-Qur'an Al-Karim.

Sejalan dengan pendapat Quraish Shihab bahwa tiada saatu bacaan seperti kitab suci Al-Qur'an yang sudah diatur tatacara membacanya, mana yang harus dipendekan, yang harus dipanjangkan, yang harus dipertebal ataupun bacaan yang harus diperhalus dalam pengucapannya, dimana tempat yang terlarang atau boleh, atau juga harus memulai dan berhenti, bahkan AlQur'an ini diatur lagam dan iramanya sampai kepada etika dan estetika cara membacanya. ${ }^{3}$

Umat Islam seharusnya lebih bersyukur, bahwa Allah Ta'ala telah memberikan sebuah kitab suci yang sangat sempurna tidak ada keraguan ayat-ayatnya. Al-Qur'an ini dinamanakan sebagai Al-Huda, As-Syifa, Al Mau'idzah dalam pebutan kitab suci Al-Qur'an. Sehingga Allah Ta'ala menjadikan Al-Qur'an ini sebagai pedoman dan petunjuk bagi kehidupan umat manusia dan rahmatan lil alamiin. Selama ini Al-Qur'an tidak berubah sebagai hiasan yang ditaruh di dalam lemari, di buat kaligrafi yang amat dipajang dan indah di dinding atau bahkan juga dijadikan mantra yang selalu diletakan di tempatempat tertentu. Tentulah hal ini sangat bertentangan dengan ajaran al-Qur'an itu sendiri yang diharapkan oleh Allah Ta'ala menawarkan dirinya untuk senantiasa dibaca dan diamalkan. Sebagaimana Allah Ta'ala telah berfirman dalam QS. AlMuzzammil: 20:

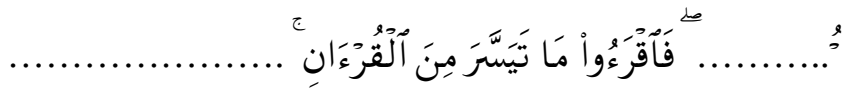

Artinya: ....."bacalah apa yang mudah (bagimu) dari Al Quran...."4

${ }^{3}$ M. Quraish Shihab, Wawasan Al-Qur'an Tafsir Tematik Atas Berbagai Persoalan Umat (Bandung: PT Mizan Pustaka, 2007), h.4

${ }^{4}$ Departemen Agama RI, Al-Qur'an Terjemahanya...., h. 455 
Kitab Suci Al-Qur'an sebagai pedoman kehidupan bagi setiap umat muslim, setiap muslim dianjurkan untuk senantiasa membacanya serta memahami kandungan isi dari setiap ayatayat yang dibacanya. Oleh sebab itu bagi kita sebagai umat Islam untuk senantiasa mempelajari Al-Qur'an, baik belajar membaca, menulis maupun mempelajari isi kandungan ayat Alqur'an. ${ }^{5} \mathrm{Al}-$ Qur'an sendiri juga menyatakan dirinya sebagai "hudan" yakni petunjuk bagi kehidupan umat manusia, memberikan cahaya kepada pikiran mereka, mendidik jiwa dan akal mereka. ${ }^{6}$ Sebagaimana diisyaratkan dalam surat Al-Isra' ayat 9:

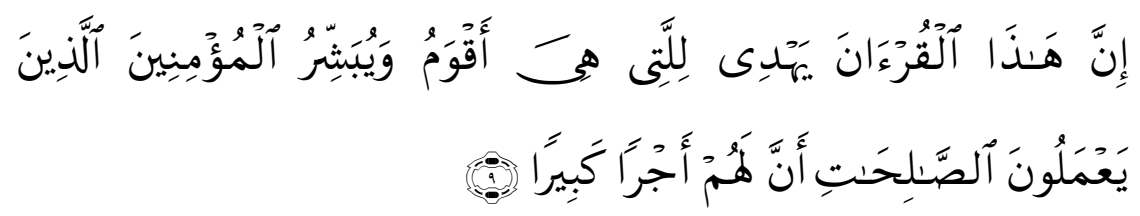

Artinya: "Sesungguhnya Al Quran ini memberikan petunjuk kepada (jalan) yang lebih Lurus dan memberi khabar gembira kepada orang-orang $M u^{\prime}$ min yang mengerjakan amal saleh bahwa bagi mereka ada pahala yang besar". (QS.Al-Isra:9) ${ }^{7}$

Dari Ayat diatas memberikan pelajaran untuk kita sebagai umat muslim diperintahkan untuk mentadabburi (memahami makna lafal-lafal Al-Qur'an) sebagai pedoman hidupnya. Supaya tidak terjadi kekeliruah dalam memahami, membaca dan mengaplikasikan makna yang terkandung dalam ayat-ayat AlQur'an dalm kehidupan sehari-hari. Sebagaimana Allah SWT mengambarkan dalam Surah Shaad ayat 29 yang berbunyi:

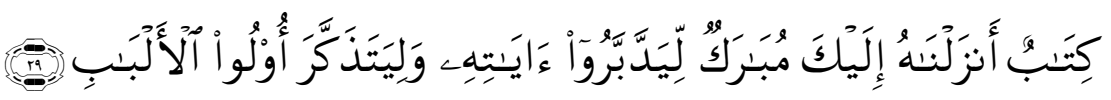

Artinya: "Ini adalah sebuah kitab yang Kami turunkan kepadamu penuh dengan berkah supaya mereka memperhatikan ayatayatNya dan supaya mendapat pelajaran orang-orang yang mempunyai fikiran". (QS. Shaad: 29)

${ }^{5}$ Muhammad Syauman Ar-Ramli. dkk, Nikmatnya Menangis bersama Al-Qur'an, (Jakarta: Instanbul, 2015), h. 18

${ }^{6}$ M. Baqir Hakim, Ulumul Qur'an, (Jakarta: Al-Huda, 2006), h. 35

${ }^{7}$ Departemen Agama RI, Al-Qur'an Terjemahanya, (Jakarta: Bintang Indonesia, 2011),hlm. 283 
Intisari dari ayat diatas bahwa kita selaku umat muslim untuk senantiasa belajar dan memperhatikan ayat-ayat Allah Ta'ala yaitu Al-Qur'an. Maka dari itu sebagai umat Islam untuk terus mempelajari ilmu Al-Qur'an supaya dapat merubah perilaku yang tidak sesuai dengan tuntunak Al-Qur'an menjadi sesuai dengan ajaran Al-Qur'an dengan cara membaca, mendengar, memahami dan mengaplikasikannya dalam kehidupan sehari-hari. Dengan denikian untuk mempermudah umat Islam dalam mempelajari dan memahami ilmu Al-qur'an, maka diperlukan sorang ulama yang ahli dalam memberikan pemahaman mengenai Al-Qur'an itu sendiri yang sering dikenal dengan "Bimbingan Agama" Pembimbing Agama ini ialah seorang yang memberikan bimbingan, pencerahan dan pengarahan kepada umatnya dalam bidang ilmu agama maupun ilmu sosial untuk senantiasa lebih meningkatkan pemahaman dan keilmuan umat atau jama'ah akan ajaran agama dan kemudian mendorong untuk selalu malakukan alam shaleh. Sebagai mana dalam sebuah hadis Rasulullah SAW di riwayatkan oleh sayyidina Ustman Bin Affan yang berbunyi:

Artinya: Dari Ustman bin Affan ra, beliau berkata, "bahwa Rasulullah SAW bersabda,"sebaik-baik kalian adalah orang yang belajar Al-Qur'an dan mengajarkannya."(HR. Bukhari $)^{8}$

Dari hadist di atas sangat jelas bahwa seorang hamba sangat mulia dihadapan Allah dan Rasulnya yang memiliki keinginan untuk terus belajar Al-Qur'an dan mengajarkannya kepada orang lain. Dalam kehidupan, seorang pembimbing agama berfungsi sebagai orang yang memberikan bimbingan dan dorongan kepada umat dan masyarakat untuk menggali potensi dan pemahanan yang harus dilakukan dalam kehidupan seharihari demi kemajuan dan keselamatan di dunia dan akhirat. ${ }^{9}$ Biasanya pembimbing agama dilaksanakan oleh para pemuka

${ }^{8}$ Imam Nawawi, Shahih Riyadhush Shalihin, (Jakarta: Pustaka Azzam Anggota IKAPI DKI, 2003), h.153

9 Departeman Agama, Panduan Tugas Operasional Penyuluh Agama Islam Utama, Direktorat Jenderal kelembagaan Agama Islam, (Jakarta: 2004), h. 8 
agama yaitu Ulama, Mubaligh, Da'i atau Kiyai yang menyampaikan langsung kepada jama'ahnya. ${ }^{10}$

Kewajiban membaca al-Qur'an sebagai wujud mempelajarinya dimulai sejak kanak-kanak sampai Tua. Mereka berhak mendapatkan bimbingan pengajaran membaca Al-Qur'an dari orang dewasa terutama dari kedua Orang Tuanya. Orang tua memikul tanggung jawab yang sangat besar untuk mengajarkan Al-Qur'an kepada anak-anak mereka agar terbebas dari buta huruf Al-Qur'an. Dengan demikian orang tua seyogyanya sudah lebih dahulu mampu memahami dan membaca Al-Qur'an sebelum mengajarkannya kepada anakanaknya.

Mungkinkan orang tua bisa mengajarkan membaca AlQur'an kepada anak-anaknya sedangkan mereka sendiri belum mampu membacanya atau bahkan tidak mengenal sama sekali tentang Al-Qur'an. Meskipun demikian seseorang yang belajar membaca Al-Qur'an adalah sebaik-baik orang Muslim dan mengajarkan Al-Qur' an kepada orang lain juga sebaik-baik orang Muslim, akan tetapi alangkah lebih baik dan sangat utama jika orang tersebut menggabungkan keduanya. Orang tersebut belajar cara membaca al-Qur'an sekaligus mengajarkan kepada orang lain apa yang telah dipelajarinya seperti yang dijalankan oleh Majelis Taklim Bandungan.

Bagi orang tua sudah terlanjur belum bisa membaca AlQur'an akan sulit mencari lembaga mana yang peduli dengan program pemberantasan buta huruf Al-Qur'an. Ada juga orang tua yang secara pribadi malu belajar Al-Qur'an kepada anaknya yang sudah bisa atau kepada orang lain yang sudah menguasai Al-Qur'an. Permasalahan seperti ini banyak dijumpai dipelosok desa, misalnya di Kampung Sawah Lega Kecamatan Pasriwangi Kab. Garut.

Namun, pada umumnya ibu-ibu Majelis Taklim Bandungan notabene dari para Petani yang memiliki kesadaran yang tinggi untuk belajar Al-Qur'an. Akan tetapi mereka merasa malu untuk belajar membaca Al-Qur'an di usia lanjut ini, apalagi dengan rutinitas yang penuh setiap harinya selalu mengurusi pertanian kepergunungan serta keluarga sehingga membuat

${ }^{10}$ Departeman Agama, Panduan Tugas Operasional Penyuluh Agama Islam Utama, h.7 
mereka memikirkan untuk belajar Al-Qur'an. Namun demikian dengan motivasi serta semangat uang kuat yang sudah melewati masa itu untuk terus istiqamah dalam belajar Al-Qur'an di Majelis Taklim Bandungan Kampung Sawah Lega Kecamatan Pasirwangi Kabupaten Garut.

Motivasi yang diberikan kepada ibu-ibu Majlis Taklim Bandungan berbeda yaitu: Wa Al-Akhirotu Khoirullaka minal ulla wal mauti, Memengtingkan kehidupan akhirat ketimbang kehidupan dunia, motivasi ini sangat mudah di ingat oleh mereka dan yang terpenting sangat memiliki makna yang luar biasa bagi seluruh jama'ahnya. Motivasi yang diberikan tidak jauh berbeda dengan motivasi yang dicontohkan Rasulullah SAW, yang tidak menyimpang dari aturan dan ketentuan Allas Ta'ala. Agama Islam adalah agama yang disampaikan kepada Nabiyullah Muhammad SAW untuk diteruskan kepada seluruh unatnya yang mengandung ketentuan-ketentuan ibadah muamalah (syariah), untuk senantiasa menjalankan segala perintahnya salah satunya dengan belajar membaca Al-Qur'an.

Berdasarkan dari Uraian di atas, Penelitian Tentang Peranan Pembimbing Agama Islam Dalam Memberikan Motivasi Pentingnya Belajar Al-Qur'an Di Majelis Taklim Bandungan Kampung Sawah Lega Kecamatan Pasirwangi Kabupaten Garut sangat menarik untuk diteliti, terutama terkait dengan pelaksanaan bimbingan. Mengingat peranan pembimbing agama Islam dalam melakukan pembinaan kepada jama'ah merupakan suatu upaya yang sangat penting dalam menunjang pembangunan di daerah pegungungan, khusunya di kampong sawah lega.

\section{B. Metode Penelitian}

Jenis penelitian yang digunakan adalah penelitian kualitatif dengan kategori penelitian lapangan. Terkait dengan penelitian Bimbingan Agama Islam yang membina di Majelis Taklim Bandungan, maka pendekatan yang dilakukan adalah melalui pendekatan fenomenologi pembimbing secara subjektif. Mengingat asumsi dasar pada pendekatan ini merupakan kemampuan menjelaskan atau menafsirkan pemikiran manusia dan tindakan (dalam hal ini tindakan dan pikiran pembimbing Agama Islam dalam memberikan motivasi belajar Al-Qur'an) 
dengan cara menggambarkan secara luas dan komprehensif struktur realitas yang tampak adanya. ${ }^{11}$

Metode yang digunakan dalam melakukan penelitian ialah dengan menggunakan Studi Kasus, karena metode ini merupakan sebuah cara kerja penelitian kualitatif paradigm naturalaistik dengan pendekatanb fenomenologi yang berusaha menguraikan dan menjelaskan secara mandala. Selain itu juga cara kerja metode studi kasus ini merupakan bagian dari paradigm naturalistic dengan pendkatan fenomenologi. Adapun data primer dan data sekunder diperoleh langsung melalui observasi, wawancara dan documenter yang dianalisis berdasarkan teknik analisis deskriptif, sehingga memperoleh data dan hasil analisis yang lebih akurat dan sesuai focus pada permasalahan penelitian.

\section{Pembahasan}

Pembimbing Agama merupakan orang yang diberikan bimbingan kepada seseorang agar dengan potensi yang dimilikinya mampu mengembangkan diri secara optimal dengan jalan memahami dan mengatasi hambatan yang ada dalam dirinya, guna untuk menentukan kehidupan masa depan yang lebih baik. Bimbingan agama secara umum adalah sebagai suatu bantuan dengan nilai-nilai keagamaan. Bimbingan agama adalah suatu proses individu melalui usahanya sendiri untuk mengembangkan kemampuan agar memperoleh kebahagiaan pribadi dan manfaat sosial. ${ }^{12}$

Pembimbing Agama menurut istilah bahasa Inggris terjemahan dari kata guidance yang berasal dari kata kerja to guide yang artinya membimbing, memajukan, menuntun ataupun membantu. Sesuai dengan istilah di atas maka secara umum Pembimbing Agama dapat dikatakan sebagai kegiatan membina dan menuntun. ${ }^{13}$

${ }^{11}$ Norman K. Denzin dan Yvonna S. Lincoln, Handbook of Qualitative Research, Trj. Dariyatno, dkk, (Yogyakarta: Pustaka Pelajar, 2011), Cet.3, 335336

${ }^{12}$ Umar Santono, Bimbingan dan Penyuluhan, (Bandung: CV. Pustaka Setia, 1998), Cet. Ke-1, h.9

${ }^{13}$ Hellen A, Bimbingan dan Konseling, (Jakarta: Quantum Teaching, 2005), h.2 
Enjang AS menyebutkan, bahwa antara bimbingan dan konseling memiliki dimensi berbeda dari proses kegiatannya. Menurut Enjang AS, proses bimbingan (Guidance) terambil dari akar kata Guid dalam literasi bahasa Inggris yang memiliki arti showing the way (memberikan penunjuk jalan), leading (menuntunkan arah jalan), conducting (memimpin ke arah jalan yang benar), giving instruction (memberikan arahan kepada jalan yang benar), regulating (mengatur agar tetap konsisten di jalan yang benar), governing (memebrikan perintah), dan giving advice (memberikan nasihat yang baik-baik). Sedangkan konseling atau causeling terambil dari kata to counsel yang artinya memberikan suatu nasihat atau ajakan kepada orang lain secara langsung, baik itu secara personal maupun kelompok. ${ }^{14}$

Motivasi merupakan suatu usaha yang sangat disadari untuk mempengaruhi tingkah laki seseorang agar senantiasa ia tergerak hatinya untuk bertindak melakukan seseuatu sehingga dapat mencapai hasil dan tujuan tertentu. Kaitannya dalam belajar membaca Al-Qur'an, motivasi belajar membaca Al-Qur'an merupakan suatu usaha yang bertujuan untuk mendoro seseorang untuik senantiasa belajar. Dalam hal ini, dimana motivasi belajar membaca Al-Qur' an ini adalah salah satu usaha yang dilakukan pembimbing agar seseorang mau belajar membaca Al-Qur'an.

Memberikan sebuah motivasi dalam bentuk bimbingan agama Islam dalam menumbuhkan rasa keinginan untuk terus menerus belajar membaca Al-Qur'an di Majelis Taklim Bandungan yang dilakukakan pembimbing dengan mengajarkan membaca Al-Qur'an. Pemberian motivasi dilakukan ketika proses bimbingan agama melalui tausiyah setelah membaca AlQur'an secara bersamaa-sama. Motivasi yang diberikan ini selalu mengingatkan kepada jama'ah untuk senantiasa belajar dirumah dan mengulang-ulang bacaannya. Disamping itu, pemberian motivasi dengan mengingatkan para jama'ah juga memberikan motivasi dengan kata-kata mutiara agar para jamaah lebih tergugah hatinya untuk selalu belajar khususnya belaja AlQur'an dan mengamalkannya.

14 Enjang AS dan Abdul Mujib, Dasar-dasar Bimbingan dan Penyuluhan Islam, (Bandung: Sajjad Publishing House, 2009), h. 50-51 
Selajan dengan fungsi motivasi belajar pada dasarnya dapat membantu dalam memahami dan menjelaskan perilaku individu yang sedang belajar. Motivasi mempunya fungsi yang sangat penting dalam belajar seseorang, karena motivasi akan menentukan intensitas usaha belajar yang dilakukan oleh seseorang. Hal ini berarti seseorang yang memiliki motivasi yang tinggi untuk belajar yang tekun dalam belajar secara terus menerus tanpa mengenal lelah dan putus asa dalam kegiatan belajarr.

Kondidi lingkungan di Majelis Taklim Bandungan ditinjau dari aspek geogerafisnya adalah daerah yang terletak jauh dari perkotaan, terletak di daerah perbukitan dan pegunungan, serta tata letak permukiman warga yang bersifat menyebar dan tidak merata, sehingga sangat berpengaruh terhadap peranan pembimng Agama Islam, terutama dalam proses kegiatan bimbingan membaca Al-Qur'an, seperti yang dilakukan di majelis taklim bandungan.

Dari hasil wawancara penulis dengan pembimbing agama dan jama'ah yang mengikuti kegiatan belajar membaca AlQur'an di Majlis Taklim Bandungan Kampung Sawah Lega Kecamatan Pasirwangi Kabupaten Garut kegiatan ini tidak terlepas dari empat aspek yaitu: pertama, waktu; kedua,tempat pelaksanaan; ketiga, materi dan yang keempat, proses kegiatan belajar membaca Al-Qur'an. Berdasarkan hasil wawancara secara mendalam di lokasi penelitian, maka proses kegiatan belajar membaca Al-Qur'an di Majelis Taklim Bandungan Kampung Sawah Lega Kecamatan Pasirwangi Kabupaten Garut telah terjadwal di setiap minggunya. Untuk waktu dan tempat pelaksanaan di Majelis taklim Bandungan pada Sabtu Malam setelah shalat Magrib atau Pukul 18.00 WIB-19.30 Malam.

Berdasarkan hasil wawancara di lokasi penelitian, Materi bimbingan merupakan hal yang sangat penting dalam pelaksanan bimbingan karena pemilihan materi yang sesuai akan membantu jama'ah mencapai suatu tujuan yang dingingkan. Sedangkan untuk aspek materi dalam kegiatan belajar membaca Al-Qur'an yang dilaksanakan di majelis taklim Bandungan sawah lega adalah berupa materi ilmu tajwid dan materi yang disesuaikan dengan terjemahan ayat Al-Qur'an yang sedang dibaca pada kegiatan tersebut. Adapun materi yang disampaikan menyesuaikan ayat yaitu tentang akidah islamiyah dan akhlak, 
tauhid dan ketaqwaan dan ilmu tentang fikih seperti tentang bersuci dan lain sebagainya.

Begitu juga memberikan tausiyah kepada para jamaah pada saat kegiatan rutinan dengan memberikan materi yang berkaitan dengan Aqidah dan Akhlak baik akhlak kepada Allah maupun akhlak ketapa sesama manusia, materi tentang fikih dan materi tentang keimanan dan ketaqwaan, dengan tujuan tidak lain agar para jamaah semuanya disamping mahir membaca AlQur'an juga dapat memahami isi dan kandungan Al-Qur'an dan mampu mengaplikasikannya dalam kehidupan sehari-hari.

Berdasarkan hasil analisis dilapangan berkaitan dengan proses kegiatan belajar Al-Qur'an di majelis taklim Bandungan maka dapat dideskripsikan diantaranya sebagai berikut: Pertama, mengawali pembacaan ayat Al-Qur'an secara berjamaah pembimbing maupun para jaamah. Kedua ,Setelah membaca ayat Al-Qur'an yang sesuai dengan kanca tadarusnya disambung dengan membaca ayat terusan hanca tadarus sambil dijelaskan tajwid dari ayat tersebut. Ketiga, Para jamaah selesai membaca maka, pembimbing memberikan penjelasan tentang isi kandungan ayat tersebut melalui tausiyah dan di dalam tausiyahnya itu ada sebuah motivasi yang disampaikan oleh pembimbing untuk para jamaah. Keempat, Sebelum diakhiri kegiatan belajar membaca Al-Qur'an biasanya disediakan waktu untuk sesi Tanya jawab dan selesai sesi Tanya jawab maka, kegiatan pengajaran Al-Qur'an ditutup dengan do'a kafaratul Majelis.

\section{Kesimpulan}

Berdasarkan hasil pembahasan, maka dapat disimpulkan bahwa Peranan Pembimbing Agama Islam Dalam Memberikan Motivasi Pentingnya Belajar Al-Qur'an secara sistematis motivasi belajar Al-Qur'an di Majelis Taklim Bandungan Sawah Lega dilakukan oleh pembimbing dengan senantiasa mengingatkan kepada para jama'ah unbtuk selalu mengulang-ulang bacaannya dirumah supaya cepat mahir dalam membaca Al-Qur'an dengan baik dan benar sesuai makhorijul huruf dan tajwidnya karena sering mutholaah atau latihan di rumah masing-masing. Peranan pembimbing agama dalam menumbungkan motivasi pentingnya belajar Al-Qur'an bagi para jamaah yang ada di Majelis taklim Bandungan yaitu dengan cara melakukan kegiatan yaitu belajar 
membaca Al-Qur'an secara berjamaah dan memberikan penjelasan tentang tajwid kepada para jamaah serta diberikan penjelasan tentang isi kandungan yang dibaca dalam kegiatan tersebut. Di samping itu, selain isi kandungan ayat yang dibaca oleh pembimbing juga menjelaskan tentang Aqidah Akhlak, ketaqwaan dan keimanan serta fikih untuk bekal para jamaah dalam mengaplikasikan kehidupan sehari-hari.

Merujuk ada kesimpulan diatas, perlu disampaikan beberapa saran atau rekomendasi. Pertama, perlunya diadadakan pengajian bapak-bapak petani ataupun warga diluar Majelis Taklim Bandungan Kampung Sawah Lega Kecamatan Pasirwangi Kabupaten Garut. Kedua, untuk memperkaya wawasan serta meningkatkan kualitas dan kuantitas keagamaan jamaah; maka perlu dihadirkannya pembimbing di luar Majelis Taklim. Hal ini demi terwujudnya Rahmatan il Alamin. Ketiga, penelitian ini masih terus memungkinkan untuk dikembangkan dan dikaji lebih dalam lagi menjadi peranan pembimbing agama lainnya, baik dari segi Toeritis, metodolohgis maupun pembahasannya.

\section{Daftar Pustaka}

A,Hellen, Bimbingan dan Konseling, Jakarta: Quantum Teaching, 2005

Ahmad Sarbini, (2010), Internalisasi Nilai Keislaman Melalui Majelis

Taklim, Jurnal Ilmu Dakwah Vol. 5 No. 16 Juli-Desember 2010

Anas Rohman,M.Pd (2016), Peran Bimbingan Konseling Islam dalam Pendidikan, Jurnal Pendidikan Agama Islam Universitas Wahid Hasyim,Vol.4 No.1 Tahun 2016

Baqir M. Hakim, Ulumul Qur'an,Jakarta: Al-Huda, 2006

Denzin, Norman K. dan Yvonna S. Lincoln. Handbook of Qualitative Research, Trj. Dariyatno, dkk. Yogyakarta: Pustaka Pelajar, 2011. Cet. 3.

Departeman Agama, Panduan Tugas Operasional Penyuluh Agama Islam Utama, Direktorat Jenderal kelembagaan Agama Islam, Jakarta: 2014. 
Departemen Agama RI, Al-Qur'an Terjemahanya, Jakarta: Bintang Indonesia, 2018.

Enjang AS dan Abdul Mujib. Dasar-dasar Bimbingan dan Penyuluhan Islam. Bandung: Sajjad Publishing House, 2009.

Fathimah, E., Isa, M., \& Kasisnawati, K. (2019). Peran Pembimbing Agama Pada Pemulung Perempuan Dalam Meningkatkan Kualitas Agama di Tempat Pembuangan Akhir (Tpa) Sukawinatan Palembang. Nurani: Jurnal Kajian Syari'ah Dan Masyarakat, 18(2), 31-40.

Gudnanto (2015), Peran Bimbingan dan Konseling Islami Untuk Mencetak Generasi Emas Indonesia. Jurnal Konseling GUSJIGANG, Vol.1, No.1 Tahun 2015 ISSN 2460-1187

Karim, H. A. (2019). Peran Manajemen Dalam Bimbingan Penyuluhan Islam. Jurnal Bimbingan Penyuluhan Islam, 1(01), 116-142.

Karim, H. A. URGENSI HALAQAH DALAM AKSELERASI DAKWAH.

M. Quraish Shihab, Wawasan Al-Qur'an Tafsir Tematik Atas Berbagai Persoalan Umat, Bandung: PT Mizan Pustaka, 2013.

Muhamad Arif Mustofa, (2016), Majelis Ta'lim Sebagai Alternatif Pusat Pendidikan Islam (Studi Kasus pada Majelis Ta'lim Se Kecamatan Natar Lampung Selatan), Jurnal Kajian Keislaman dan Kemasyarakatan, Vol.1, No.01, 2016

Nawawi Imam, Shahih Riyadhush Shalihin, (Jakarta: Pustaka Azzam Anggota IKAPI DKI, 2015.

Rohman, F. (2019). Konsep Jiwa Yang Tenang dalam Surat Al Fajr 27-30 (Perspektif Bimbingan Konseling Islam). Jurnal Al-Irsyad: Jurnal Bimbingan Konseling Islam, 1(2), 219234.

Santono Umar, Bimbingan dan Penyuluhan, (Bandung: CV. Pustaka Setia, 1998), Cet. Ke-1,

Syauman Muhammad Ar-Ramli. dkk, Nikmatnya Menangis bersama Al-Qur'an, Jakarta: Instanbul, 2015. 
Wahyudin, R. D. N. (2020). FILOSOFIS KEBENARAN FIKSI SEBAGAI PENGEMBANGAN INTELEGENSI BAGI KEHIDUPAN INDIVIDU MANUSIA. Jurnal Bimbingan Penyuluhan Islam, 1(2), 269-296.

Walgito, Bimbingan Penyuluhan di Sekolah, Yogyakarta: Andi Offset,2010

Widodo, A. (2019). Dakwah di Era Revolusi Industri 4.0. khabar, l(1), 49-65.

Widodo, A. (2019). URGENSI BIMBINGAN KEAGAMAAN ISLAM TERHADAP PEMBENTUKAN KEIMANAN MUALAF. Jurnal Bimbingan Penyuluhan Islam, 1(01), 6690. 